\title{
Influence of stress ratio on residual stress evolution near cold- expanded hole due to low-cycle fatigue by crack compliance data
}

\author{
A.V. Chernov, S. I. Eleonsky, V.S. Pisarev \\ Central Aero-Hydrodynamics Institute named after Prof. N.E. Zhukousky (Ts AGI). 1 Zbukovsky Street, Zhukovsky 140180 \\ Moscow Region, Russia. \\ andchern@rambler.ru,bttps://orcid.org/0000-0003-4020-1643 \\ juzzepka@mail.ru, bttps://orcid.org/0000-0003-4345-067X \\ VSP5335@mail.ru, bttps://orcid.org/0000-0002-5378-609X
}

\begin{abstract}
Modified version of the crack compliance method is used for determination of stress intensity factor (SIF) related to narrow notches emanating from cold-expanded holes. These notches are inserted at different stages of low-cycle fatigue under constant external load. It is shown how residual SIF values, generated by residual stress field influence, can be separated from total experimental SIF values. Residual SIF values, obtained at different stage of low-cycle fatigue with the same stress range $\Delta \sigma=350 \mathrm{MPa}$ but different stress $R=-0.4$ and $R=-1.0$, provide quantitative description of residual stress evolution near cold-expanded hole. It shown that maximal residual stress relaxation of order 20 per cent occurs at 95 lifetime per cent for both loading programs.
\end{abstract}

KEYwORDS. Metal-composite joints; Cold hole expansion; Residual stress intensity factor; Residual stress.

\section{OPEN ACCESS}

Citation: Chernov, A.V., Eleonsky, S. I., Pisarev, V.S., Influence of stress ratio on residual stress evolution near cold-expanded hole due to low-cycle fatigue by crack compliance data, Frattura ed Integrità Strutturale, 55 (2021) 174-186.

Received: 25.11 .2020

Accepted: 02.12.2020

Published: 01.01.2021

Copyright: (C) 2021 This is an open access article under the terms of the CC-BY 4.0, which permits unrestricted use, distribution, and reproduction in any medium, provided the original author and source are credited.

\section{INTRODUCTION}

I t has earlier been shown how localized displacement measurements, based on electronic speckle-pattern interferometry, can be implemented to obtain notch mouth opening displacement (NMOD), stress intensity factor (SIF) and T-stress values for narrow notches of different length emanating from cold-expanded holes [1]. A sequence of these notches, inserted under the constant external load, serves for crack modelling at different stages of low-cycle fatigue. The approach developed has been effectively implemented for quantitative description of low-cycle damage accumulation at the vicinity of through hole in plane rectangular specimens [2]. Obtained experimental information might be very useful for verification of various numerical and theoretical methods of fatigue damage quantifying [3-4]. Another application of created methodology, that is the subject of present paper, resides in investigation of residual stress evolution near cold-expanded hole caused by cyclic loading.

Advanced aircraft structures include various metal-composite bolted joints [5]. Cold-expanded holes are the essential component of such structural elements. Cold expansion, widely used in aircraft industry, eventually leads to enhance the fatigue life of structures with fastener holes [6]. The cold working introduces a zone of compressive residual stresses around 
the hole. Fatigue life improvement is mainly related to the circumferential residual stress influence that, firstly, delays the initial crack appearance increasing the damage tolerance life. Secondly, residual stress influence leads to reducing the effective range of SIF thus decreasing fatigue crack growth [7].

Residual stresses have a beneficial effect on lifetime of pin/rivet joints with cold-expanded holes. Thus, information related to initial residual stress level as well as residual stress evolution is of decisive importance for reliable lifetime estimation. A set of both numerical and experimental methods has been developed and realized to consider the first from above problems [8-17]. But only few experimental works concern an evolution of deformation parameters and residual stresses [18-20]. One of them employs non-contact full-field strain measurements using both digital image correlation (DIC) and thermoelastic stress analysis (TSA) [18]. Derived data serve to compare the strains during crack growth around holes that had and had not been cold-expanded by 4\%. The objects of investigation were rectangular coupons made from 2024-T3 aluminum alloy, half had simple open, unexpanded holes and half had cold-expanded open holes. A DIC system was used to monitor the mandrel entry face of the coupon while a TSA system was used to monitor the mandrel exit face of the coupon during cyclic tensile loading by three programs (2024-T3, yield limit $\sigma_{y}=310 \mathrm{MPa}$; stress ratio $R=0.1$; stress range $\Delta \sigma=184.8$, 192.5 and $217.8 \mathrm{MPa}$ ). These two systems provide the measurements of simultaneous mandrel entry and exit surface strains surrounding a crack initiating from a plain and cold-expanded hole. Cracks originating from the unexpanded hole exhibit a strain field around the crack tip which is characteristic of a mode I fatigue crack while those emanating from the coldexpanded holes show a significantly lower distribution of strains around the crack tip. Crack opening displacements evaluated from the strain data obtained from DIC, are substantially reduced by the residual compressive stresses from cold expansion, while the overall fatigue data show the life improvement achieved at various applied stress levels. The most important outcome consists of dependencies between crack opening displacements and fatigue crack length constructed for crack lengths of 1, 2 and $3.7 \mathrm{~mm}$ for coupons with plain and cold-expanded holes. But these data are of difficult use to predict residual stress evolution.

Experimental approach aimed to describing residual stress evolution due to cyclic loading by the crack compliance (slitting) method is presented in work [19]. Residual stress measurements were made in aluminum 7075-T651 plates with coldexpanded holes. The yield limit $\sigma_{y}$ and ultimate tensile strengths of 7075-T651 aluminum alloy were 541 and $568 \mathrm{MPa}$,

respectively. The loading cycles parameters are: $R=0.1 ; \Delta \sigma=182.1,204.1$ and $225.5 \mathrm{MPa}$. Residual stresses were represented by symmetric Legendre polynomials on opposite sides of the hole and compliance functions found by finite element analysis. Measured residual stresses were smaller than predicted by finite element analysis. Residual stress relaxation caused by cyclic loading was not observed even though two short cracks were formed between 45,000 and 50,000 cycles in the specimen cycled at $\Delta \sigma=205 \mathrm{MPa}$ for $\mathrm{R}=0.1$. The main drawback resides in the fact that that the initial point of a cut sequence, which is used for residual stress evaluation, is located at the external edge of the specimen, but not at the hole edge.

The technique, which employs the secondary hole drilling and further measurements of hole diameter increments in principal stress directions by electronic speckle-pattern interferometry (ESPI), has been implemented to quantify residual strain evolution caused by low-cycle fatigue [20]. The cycles parameters are: $R=-0.4 ; \Delta \sigma=350 \mathrm{MPa}$. It was shown that residual strain evolution cannot be characterized as monotonic relaxation.

Present paper has common features with all three above-mentioned works. The first of them resides in implementing fullfield measurement techniques as in works [18, 20]. The crack compliance method is the base of this paper and work [19]. The first distinctive point of the approach involved in present paper consists of combining the crack combining method and ESPI displacement measurement along narrow notch border. Notch emanation from the hole edge is the second trait. The third feature resides in consideration of two low-cycle fatigue programs with negative stress ratio. Deriving new information, which is related to residual stress redistribution near cold-expanded holes in plane rectangular specimens under low-cycle fatigue with different cycle parameters, is the main goal of this paper. Further investigations will be directed toward a study of residual stress evolution in composite fragments of metal-composite joints.

\section{EXPERIMENTAL PROCEDURE}

\section{Specimens and loading program}

A luminium coupons of dimensions $180 \times 30 \times 5 \mathrm{~mm}$, each of which includes centred open hole of nominal diameter $2 r_{0}=4.0 \mathrm{~mm}$ (Fig. 1) are the objects of present study. Whole set of specimens consists of 16 units. All coupons are manufactured from a single material bar by the same technology. Absence of residual stresses in all specimens 
follows from data of probe hole drilling and further optical interferometric measurements of deformation response to local material removing [21]. Mechanical properties (elasticity modulus $E=74,000 \mathrm{MPa}$, yield stress $\sigma_{y}=330 \mathrm{MPa}$ and Poisson's ratio $\mu=0.33$ ) are obtained proceeding from standard tensile tests.

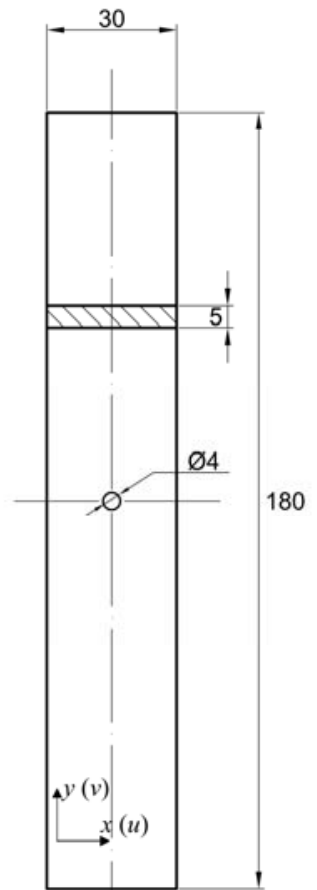

a

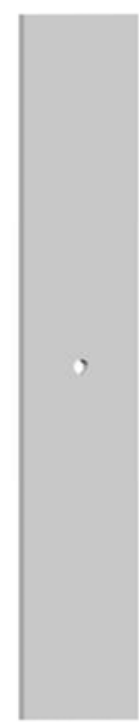

$\mathrm{b}$

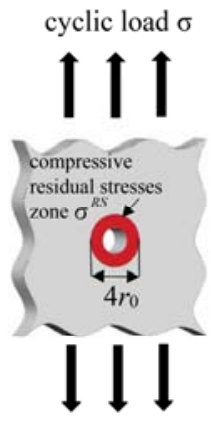

cyclic load $\sigma$

Figure 1: Drawing of specimens of T5H type. (a) scheme, (b) 3D view, (c) cyclic loading of cold-expanded hole.

All specimens have been tested after cold hole expansion. The technology of the involved procedure is described in work [1]. The expansion level is $5 \%$ of nominal interference, defined as the ratio of the interference value to the hole radius. The results of research [11], obtained by finite element simulation, evidence that the degree of interference from $4 \%$ to $6 \%$ leads to the arising circumferential residual stress $\sigma^{R S}=-(250 \div 300)$ MPa near expanded hole boundary. The exact value of $\sigma^{R S}$ depends on the yield stress of aluminium alloy. Optical interferometric measurements of the local deformation response to notch length increment are performed in the mandrel entrance (inlet) surface of all specimens.

Specimens are divided by two groups. The first of them, denoted as T5-H1, includes 8 specimens. Required SIF values are obtained at different stages of low-cycle fatigue with stress range $\Delta \sigma=350 \mathrm{MPa}$ and stress ratio $\mathrm{R}=-0.4$. Maximum remote tensile stress for this loading program is equal to $\sigma_{\max }=250 \mathrm{MPa}$ that corresponds to 0.76 of yield stress $\sigma_{y}=330 \mathrm{MPa}$.

Eight specimens from the second group $(\mathrm{T} 5-\mathrm{H} 2)$ are tested at different stages of fatigue loading program with the parameters $\Delta \sigma=350 \mathrm{MPa}, R=-1.0$. The cycle parameters expressed in the terms of maximum tensile and minimum compressive stress are equal to $\sigma_{\max }=-\sigma_{\min }=175 \mathrm{MPa}$. The value of $\sigma_{\max }=175 \mathrm{MPa}$ corresponds to 0.53 of yield stress $\sigma_{y}=330 \mathrm{MPa}$. Static strength of coupons with cold-expanded holes was not estimated because of limited number of specimens.

A sequence of narrow notches is used for crack modelling at different stages of fatigue loading. Step-by-step procedure of crack length increasing is performed by narrow jewellery saw of width $\Delta b=0.2 \mathrm{~mm}$. The original points of each symmetrical notch are located at the intersection of the hole boundary and the short symmetry axis of the specimen. Details of experimental procedure are described in works $[1,22]$. The first specimen, which is common for both groups, is tested before fatigue loading. Other specimens are subjected to fatigue loading according to the above-mentioned programs. An electro-mechanical testing machine walter + bai ag, Type LFM-Z 200, with load range $0-200 \mathrm{kN}$ is used for fatigue loading. The number of loading cycles for each investigated specimen is listed in Tab. 1 and Tab. 2 for specimens of T5-H1 and T5$\mathrm{H} 2$ group, respectively. Two specimens serve for lifetime estimation. Fracture of specimens is occurred after $N_{F 1}=6300$ 
cycles for specimen T5_H1 and $N_{F 2}=15800$ cycles for specimen T5-H2. Each specific cycle number from Tab. 1 and 2 indicates the stage of fatigue loading, at which SIF values are derived for cracks of different lengths from initial experimental data. Three consecutive notches after fatigue loading of specimens are inserted under the constant external load that corresponds to remote stress $\sigma=80 \mathrm{MPa}$. An electro-mechanical testing machine walter + bai ag, Type LFM-L 25, with loading range $0-25 \mathrm{kN}$ serves for applying remote tensile stress during the measurement procedure.

\begin{tabular}{lcccccccc}
\hline Specimen & T5_20H & T5_13H & T5_16H & T5_12H & T5_18H & T5_19H & T5_17H & T5_H1 \\
$\begin{array}{l}\text { Number of } \\
\text { cycles, } N\end{array}$ & 0 & 1000 & 2000 & 3000 & 4000 & 5000 & 6000 & 6300 \\
Lifetime, $\%$ & 0 & 16 & 32 & 48 & 63 & 79 & 95 & 100 \\
\hline
\end{tabular}

Table 1: Nomenclature of T5-H1 specimens and fatigue loading program.

\begin{tabular}{lccccccccc}
\hline Specimen & T5_20 & T5_21 & T5_22 & T5_23 & T5_24 & T5_25 & T5_26 & T5_27 & T5_H2 \\
Number of & $\mathrm{H}$ & $\mathrm{H}$ & $\mathrm{H}$ & $\mathrm{H}$ & $\mathrm{H}$ & $\mathrm{H}$ & $\mathrm{H}$ & $\mathrm{H}$ & \\
cycles, $N$ & 0 & 1000 & 2000 & 3000 & 6000 & 9000 & 12000 & 15000 & 15800 \\
Lifetime, $\%$ & 0 & 6 & 13 & 19 & 38 & 57 & 76 & 95 & 100 \\
\hline
\end{tabular}

Table 2: Nomenclature of T5-H2 specimens and fatigue loading program.

\section{Initial experimental information}

Initial experimental information has the form of interference fringe patterns, which describe the distributions of both inplane displacement components near the crack tip. These interferograms correspond to increasing the length of the central symmetrical crack of mode I in thin rectangular plate under constant tensile load. The total crack length consists of three prolongation increments. Interference fringe patterns obtained for different notch length increments in specimen T5-20H and T5-16H are shown in Fig. 2 and 3, respectively. Demonstrated high quality of interferograms in Fig. 2 and 3 is inherent in all fringe patterns obtained at all investigated stages of low-cycle fatigue (see Tab. 1 and 2).

Symmetrical configuration of fringe patterns in Fig. 2 and 3 with respect to the crack line clearly demonstrates the validity of mode I conditions. The same takes place for all crack length increments considered for all specimens. This means that SIF values can be reliably derived from the relationships developed for modified version of the crack compliance method [22]. These formulae are based on principals of linear fracture mechanics. But there is one important problem to be considered. It resides in a question how material plastic deformation inherent in the nearest vicinity of cold-expanded hole influences on a crack modelling by narrow notches. Cold expansion induces a zone of residual compressive stress around and through a hole, typically extending at least one radius around hole in the radial direction. The problem of implementing linear fracture mechanics formulae to SIF determination near cold-expanded holes is a question of further discussion.

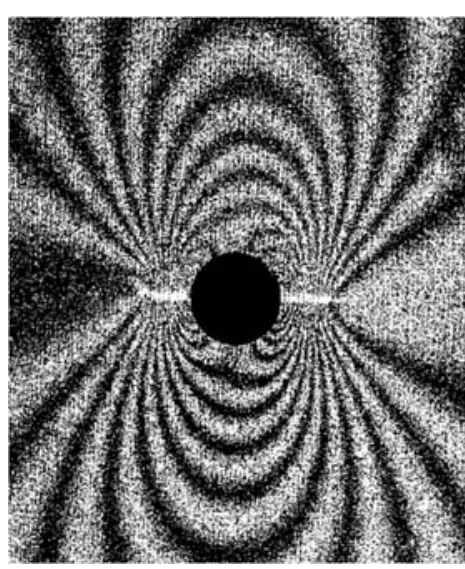

a

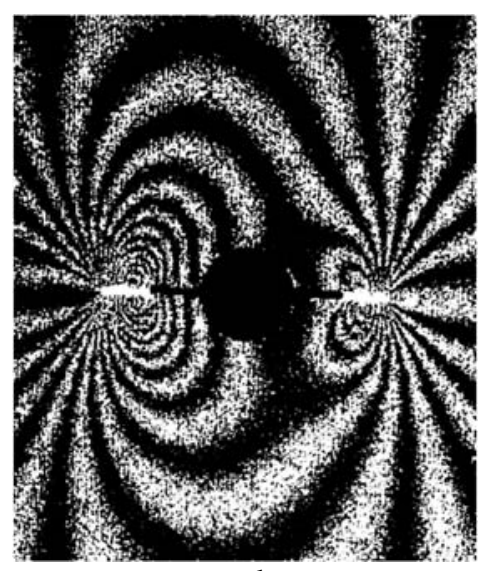

$\mathrm{b}$

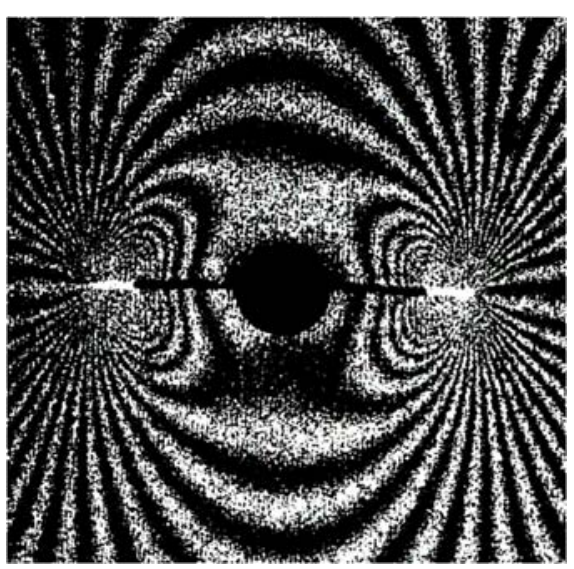

$\mathrm{C}$

Figure 2: Interference fringe patterns obtained in terms of in-plane displacement component $v$ for specimen T5_20H. 
a - initial crack length $a_{0}=0$ with the increment $\Delta a_{1}^{-}=2.28 \mathrm{~mm}$ (left) and $\Delta a_{1}^{+}=2.31 \mathrm{~mm}$ (right); b - initial crack length $a_{1}^{-}=2.28 \mathrm{~mm}$ with the increment $\Delta a_{2}^{-}=1.96 \mathrm{~mm}$ (left) and initial crack length $a_{1}^{+}=2.31 \mathrm{~mm}$ with the increment $\Delta a_{2}^{+}=2.17 \mathrm{~mm}$ (right); c - initial crack length $a_{2}^{-}=2.28 \mathrm{~mm}$ with the increment $\Delta a_{3}^{-}=1.79 \mathrm{~mm}$ (left) and initial crack length $a_{2}^{+}=4.24 \mathrm{~mm}$ with the increment $\Delta a_{3}^{+}=2.08 \mathrm{~mm}$ (right).

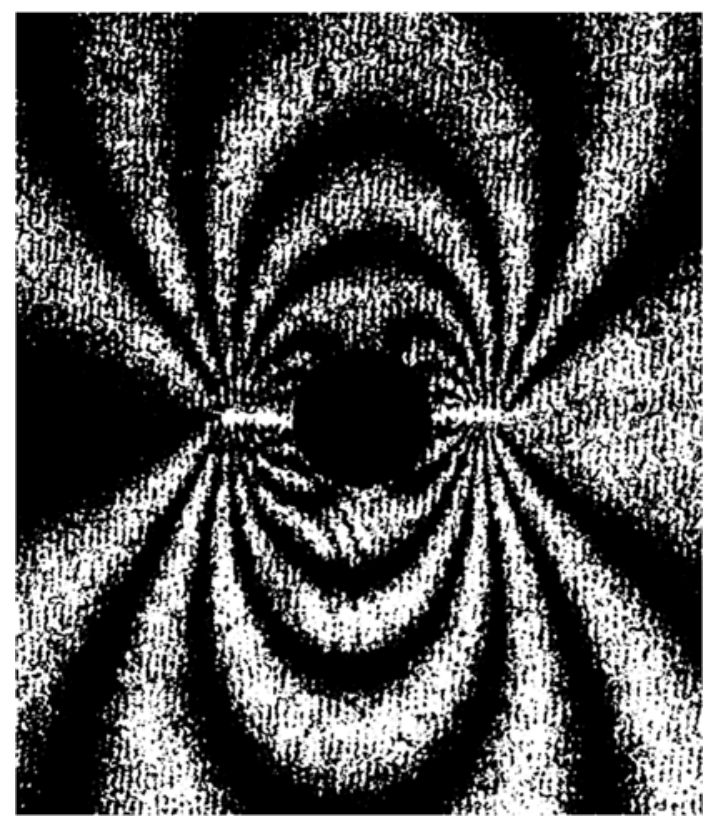

a

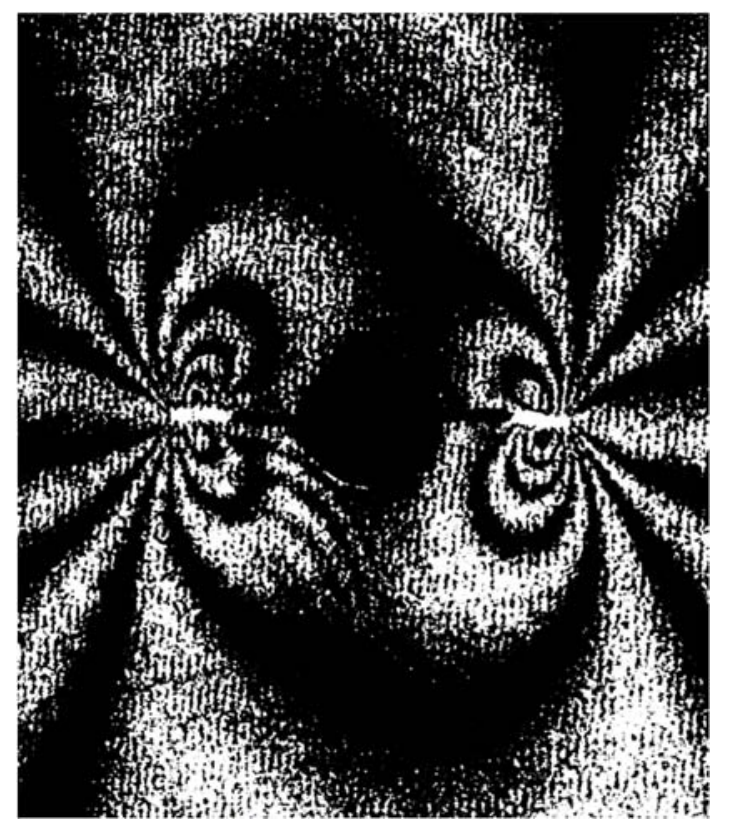

$\mathrm{b}$

Figure 3: Interference fringe patterns obtained in terms of in-plane displacement component $v$ for specimen T5_16H.a - initial crack length $a_{0}=0$ with the increment $\Delta a_{1}^{-}=2.17 \mathrm{~mm}$ (left) and $\Delta a_{1}^{+}=2.10 \mathrm{~mm}$ (right); $\mathrm{b}-$ initial crack length $a_{1}^{-}=2.17 \mathrm{~mm}$ with the increment $\Delta a_{2}^{-}=1.89 \mathrm{~mm}$ (left) and initial crack length $a_{1}^{+}=2.10 \mathrm{~mm}$ with the increment $\Delta a_{2}^{+}=1.82 \mathrm{~mm}$ (right).

\section{PARAMETERS EXTRACTION}

$\mathrm{R}$ esidual stress evolution analysis, presented in this paper, is based on redistribution of stress intensity factors, which are obtained at different stages of low-cycle fatigue. These SIF values are related to a sequence of narrow notches, initial point of which is located at the edge of cold-expanded hole. That is why an accuracy of SIF determination for notches emanating from hole of diameter $2 r_{0}=4 \mathrm{~mm}$ should be carefully established. Comprehensive uncertainties analysis inherent in fracture mechanics parameters determination by a modified version of the crack compliance method is presented in work [22]. But this analysis concerns quantitative SIF characterization for notches emanating from small hole of $0.5 \mathrm{~mm}$ diameter.

\section{Uncertainty estimation}

To reach above-declared goal two specially designed tests have been performed. The first of them is connected with asserting the measurement errors evaluation for rectangular specimen, denoted as T5_08, with plain hole, geometrical parameters of which are shown in Fig. 1. The essence of the methodology involved resides in comparison of real interference fringe patterns and analogous artificial images. This approach is a powerful instrument for fine verification of measurement results when initial experimental information is presented in the form of interference fringe patterns [20,21, 23, 24]. Interference fringe pattern obtained for specimen T5_08 with symmetrical crack for tensile load value $P=7.96 \mathrm{kN}$ are shown in Fig. $4 \mathrm{a}$. Special attention was paid to make symmetrical crack with left and right branch of equal length.

Simulation of reference fringe patterns involves a high-quality transition model that connects the object geometry in conjunction with an external load and the required in-plane displacement fields related to the object surface. In our case this model follows from the relationships of the elasticity theory. Visualization of reference fringe patterns is founded upon the 
basic relations of speckle interferometry [25]. Numerical solution, which corresponds to the difference between stress state of cracked specimen after notch formation and initial stress state of the specimen with an open plain hole only, is able of constructing a set of required reference fringe patterns. To reach this goal, a value of external load and width of real cut, which correspond to measurement conditions, have to be given. Numerical determination of displacement component fields has to be based on a high-precision finite element solution of two stress concentration problems. In the case involved the first of them resides in uniaxial tension of rectangular plate of dimensions $180 \times 30 \times 5 \mathrm{~mm}$ with central through hole of diameter $2 r_{0}=4.00 \mathrm{~mm}$. The second problem to be considered is uniaxial tension of the same plate with narrow notch of width $\Delta b=0.20 \mathrm{~mm}$ and of average length $\tilde{a}_{1}=2.64 \mathrm{~mm}$. The original point of each symmetrical notch is located at the intersection of hole boundary and transverse symmetry axis of the specimen as it shown in Fig. 1. Numerical data, describing the local displacement fields, are obtained by means of corresponding segments of the MSC.Nastran software. The finite element mesh consists of 101000 plane shell elements of CQUAD4 type. Then the reference fringe patterns can be constructed by using the difference of corresponding in-plane displacement components for two above-mentioned elasticity problems.
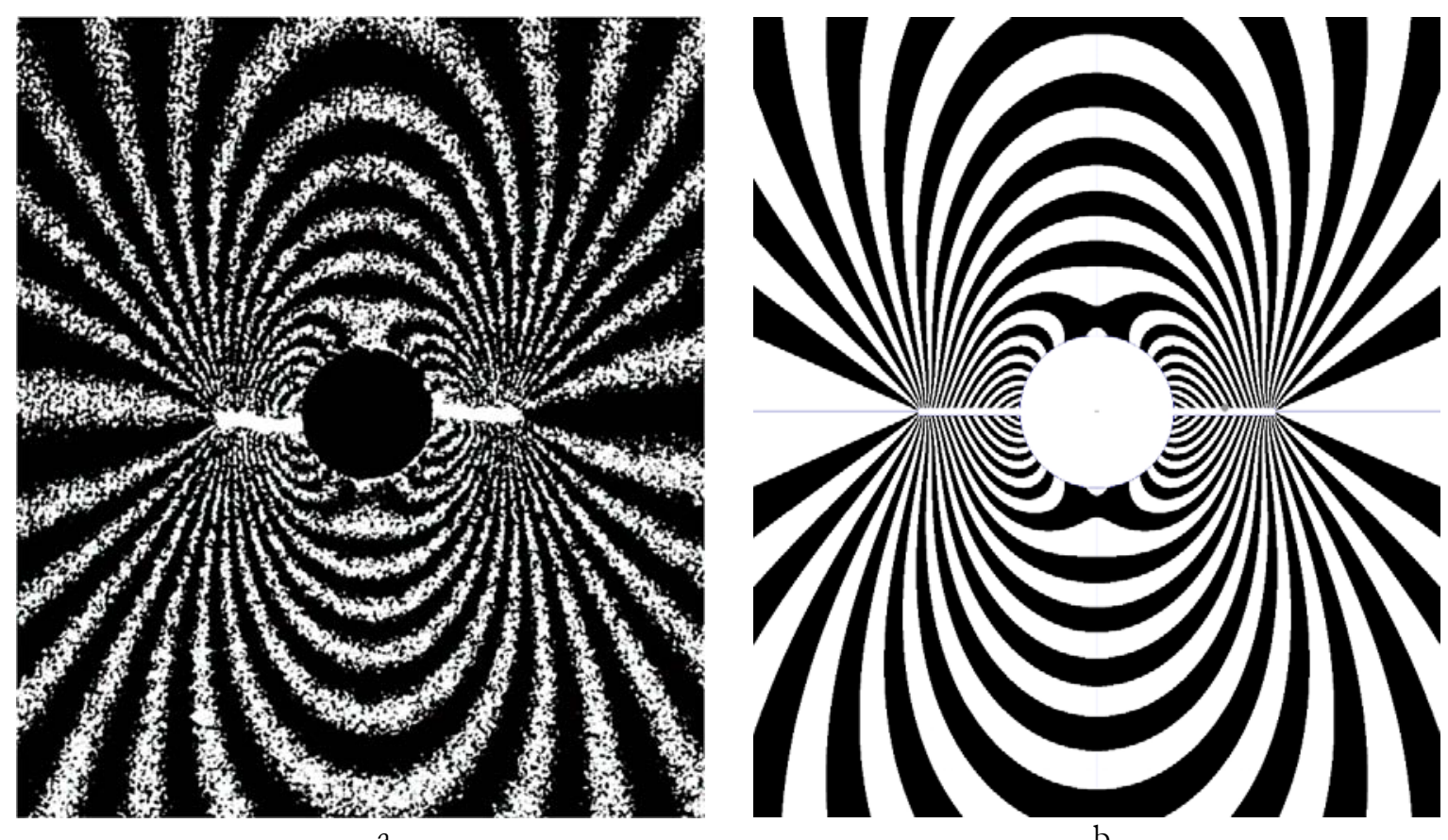

b

Figure 4: Real (a) and reference (b) interference fringe patterns obtained in terms of in-plane displacement component $v$ for specimen T5_08; initial crack length $a_{0}=0$ with the increment $\Delta a_{1}^{-}=2.66 \mathrm{~mm}$ (left) and $\Delta a_{1}^{+}=2.62 \mathrm{~mm}$ (right).

\begin{tabular}{|c|c|c|c|c|}
\hline \multicolumn{2}{|c|}{ Stage number, $n$} & 1 & 2 & 3 \\
\hline \multicolumn{2}{|c|}{$\tilde{a}_{n}=\left(a_{n}^{-}+a_{n}^{+}\right) / 2, \mathrm{~mm}$} & 2.64 & 4.20 & 6.18 \\
\hline \multirow{2}{*}{$\Delta \tilde{v}_{n-1}, \mu \mathrm{m}$} & Experiment & 12.16 & 13.40 & 14.43 \\
\hline & FEM & 13.68 & & \\
\hline \multirow{2}{*}{$\Delta \tilde{v}_{n-0.5}, \mu \mathrm{m}$} & Experiment & 9.60 & 10.64 & 11.78 \\
\hline & FEM & 10.07 & & \\
\hline \multirow{3}{*}{$\begin{array}{l}\text { SIF value, } \\
\mathrm{MPa} \times \sqrt{\mathrm{m}}\end{array}$} & Experiment, $\tilde{K}_{I}^{n}$ & 6.76 & 8.95 & 10.77 \\
\hline & $\mathrm{FEM}, K_{I}^{\mathrm{FEM}}$ & 6.70 & & \\
\hline & Theory, $K_{I}^{T}$ & 6.73 & 7.46 & 8.45 \\
\hline
\end{tabular}

Table 3: Deformation and force fracture mechanics parameters for specimen T5_08. 
Artificial interference image related to the first crack length increment is denoted by letters b in Fig. 4. A good coincidence in a configuration of real interferogram and analogous reference fringe pattern is quite evident. Averaged notch mouth opening displacement (NMOD $\Delta \tilde{v}_{n-1}$ ), notch opening displacement related to half of the crack length (NOD $\left.\Delta \tilde{v}_{n-0.5}\right)$ and $\operatorname{SIF}\left(\tilde{K}_{I}^{n}\right)$ values are used to compare experimentally and numerically obtained fracture mechanics parameters in the case of symmetrically centred cracks as it is reflected in Tab. 3. This is specially done, because ensuring equal crack length increments for both tips of symmetrical crack is quite a serious technical problem. But this difficulty is technically avoided for the first crack length increment $\Delta a_{1}^{-}=\Delta a_{1}^{+}$.

Values of NMOD and NOD obtained experimentally and numerically differ by $11 \%$ and $4.7 \%$, respectively. The SIF values, calculated by using the real and artificial interference fringe patterns for the first crack length $\tilde{a}_{1}$ as a source of initial information, are equal one to another. This very good result follows from data of Tab. 3. It should be taken into account that the reference fringe pattern is obtained as the solution of stress concentration problem in terms of in-plane displacement component $u$ and $v$. Only the final step employs linear fracture mechanics relationships in the form of Williams' infinite series for each in-plane displacement component. The formula, used for SIF values determination, has the following form [22]:

$$
K_{I}^{n}=\frac{\sqrt{2 \pi} E}{8 \sqrt{\Delta a_{n}}}\left\{2 \sqrt{2} \Delta v_{n-0.5}-\Delta v_{n-1}\right\},
$$

where $E$ is the elasticity modulus of the material; $\Delta a_{n}$ is the crack length increment. The SIF values are obtained by substituting NMOD and NOD values from Tab. 3 into formula (1). The source of the initial information is the real and reference interference fringe pattern for experimental and numerical SIF values, respectively. Note that SIF determination through the use of in-plane displacement component is very powerful numerical procedure in the course of finite element simulation of cracks in plane specimens [26]. Moreover, data thus obtained might be very useful for refining numerical models, which serves for quantifying the crack tip surface displacements in the zone where the corner point of the crack front intersects a free surface $[27,28]$.

Further accuracy analysis of the experimentally obtained SIF values is based on comparison with the analytical results presented in the famous handbook of Murakami [29]. One of the rows in Tab. 3 includes theoretical SIF values. These data correspond to the solution for the through symmetrical crack starting from the hole boundary in the infinite plane (section 5.1 of handbook [29]). Theoretical and experimental SIF values for the first crack length $\tilde{K}_{I}^{1}$ are in a good coincidence. The values of $\tilde{K}_{I}^{2}$ and $\tilde{K}_{I}^{3}$ obtained experimentally and theoretically differ by $16 \%$ and $21 \%$, respectively, with experimental SIF values exceed analogous theoretical data. This fact reflects the influence of the specimen edges that is not taken into account by the theoretical solution when through hole is located in an infinite plate. The same trend takes place when the experimental SIF values for mode I crack are compared with the theoretical data obtained for a crack in an infinite plane and a crack in a plane specimen of limited width under uniaxial tension [22]. Comparison of the experimental, numerical and theoretical data presented above clearly demonstrates that the developed approach ensures the appropriate accuracy of SIF determination in the considered case.

\section{Determination of residual stress intensity factor}

The essence of modified version of the crack compliance method resides in the following. Initial experimental information, derived in terms of crack opening displacements, is used for deriving the first four coefficients of Williams' asymptotic series and further calculations of SIF values. This means that formula (1) is based on principal of linear fracture mechanics. Thus, an influence of high-level plastic strains, which occur at the hole vicinity due to cold expansion, on formula (1) validity should be carefully considered. There is a hope to receive positive answer on this question because narrow notch, used for crack modelling, is inserted after complete redistribution of plastic strains in work-hardening aluminium alloy.

Determination of SIF values for notches emanating from cold-expanded hole, which are related to different remote stress levels, is the essential step in this way. To do this, special experiments, connected with a determination of NMOD and SIF values for three remote stress levels, have been performed. Interference fringe patterns obtained for the first notch of $\tilde{a}_{1}$ $=2.3 \mathrm{~mm}$ length under remote stress $\sigma=60,80$ and $100 \mathrm{MPa}$ are shown in Fig. 5a, 5b and 5c, respectively.

Dependencies of NMOD and SIF values from remote stress level, obtained as the result of three specimens testing, are shown in Fig. 6a and 6b, respectively. Plot in Fig. 6b has practically linear character. This fact means that formula (1), based 
in principals of linear fracture mechanics, can be reliably implemented for SIF determination when narrow notch is inserted in material volume that has been undergone to preliminary plastic deformation.

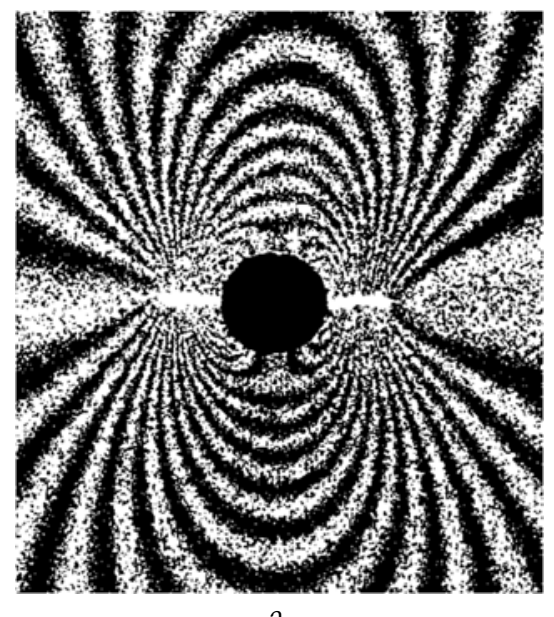

a

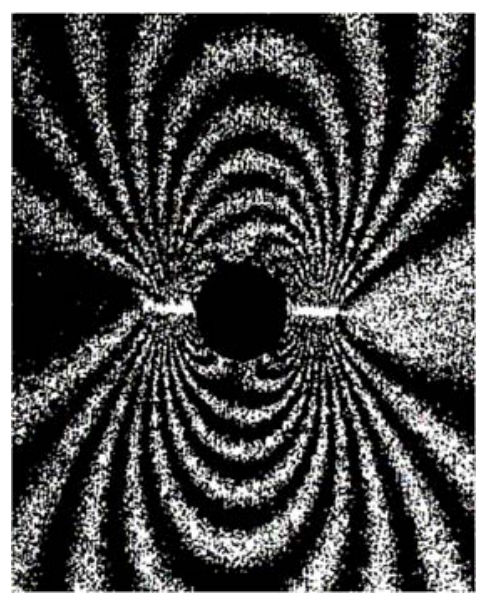

b

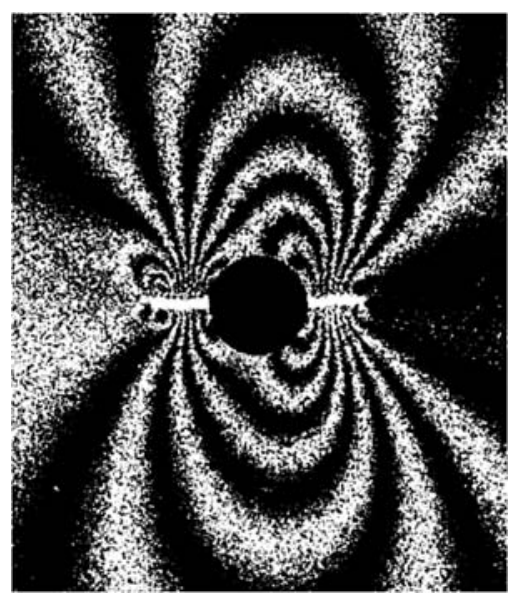

C

Figure 5: Interference fringe patterns obtained in terms of in-plane displacement component $v$ for three different specimens; initial crack length $a_{0}=0 \mathrm{~mm}$ with increment $\Delta a_{1}^{-}=2.30 \mathrm{~mm}$ (left) and $\Delta a_{1}^{+}=2.30 \mathrm{~mm}$ (right). a - Specimen T5_29H $(\sigma=60 \mathrm{MPa}) ; \mathrm{b}-$ Specimen T5_20H $(\sigma=80 \mathrm{MPa}) ; \mathrm{c}-$ Specimen T5_28H $(\sigma=100 \mathrm{MPa})$.

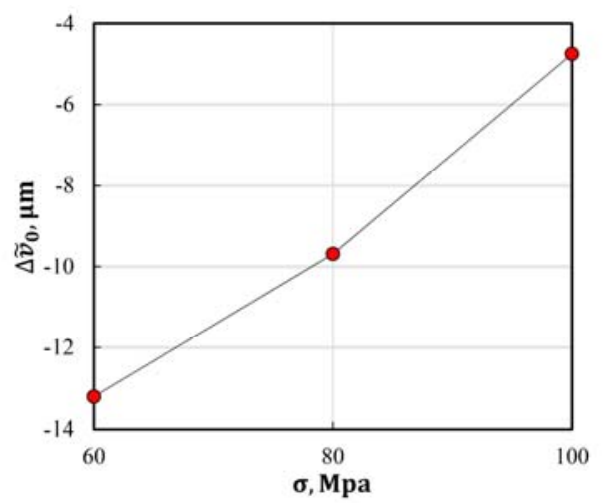

a

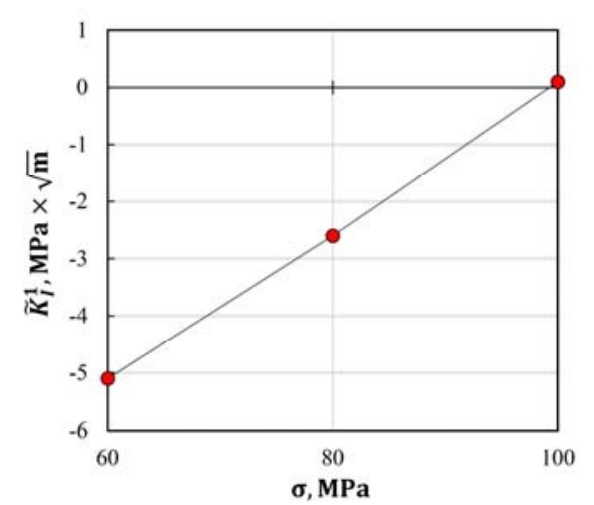

$\mathrm{b}$

Figure 6: Average values of NMOD . $\Delta \tilde{v}_{0}(\mathrm{a})$ and SIF (b) as a function of remote stress level $\sigma$.

Complete set of data, required for residual stress evolution study near cold-expanded holes due to low-cycle fatigue, has previously been reported in work [1]. The whole set of interference fringe patterns is the source of initial experimental data, which represent in-plane displacement components measured by electronic speckle-pattern interferometry in the vicinity of the notch tip. This information gives distributions of NMOD, SIF and T-stress values along total crack length in specimens of both groups, obtained for different loading cycles. These distributions can be reconstructed to receive dependencies of fracture mechanics parameters for notches of fixed length against of loading cycle number. Present analysis is founded upon redistribution of SIF values obtained for notches of different length at different stages of low-cycle fatigue. Dependencies of SIF values from number of loading cycle are shown in Fig. 7a and 7b for specimens of T5-H1 and T5-H2 group, respectively.

Considering these results, we should keep in mind that they are referred to the mandrel entrance (inlet) surface specimens. It has previously been shown that residual stresses arising at the inlet surface are always lower than those related to the outlet surface [7-17]. This means that fatigue crack always initiation point is always located at the hole edge corresponding to the inlet face where the lower compression residual stresses arise due to cold expansion. That is why optical interferometric measurements of the local deformation response to small notch length increment are performed in the mandrel entrance (inlet) surface of specimens. Thus, the thickness effect is not taken into account. To reach this aim, 
simultaneous measurements of deformation response, caused by local material removing, on both specimen faces have to be involved. A set of required experiments is currently under consideration. The results obtained will be reported later.

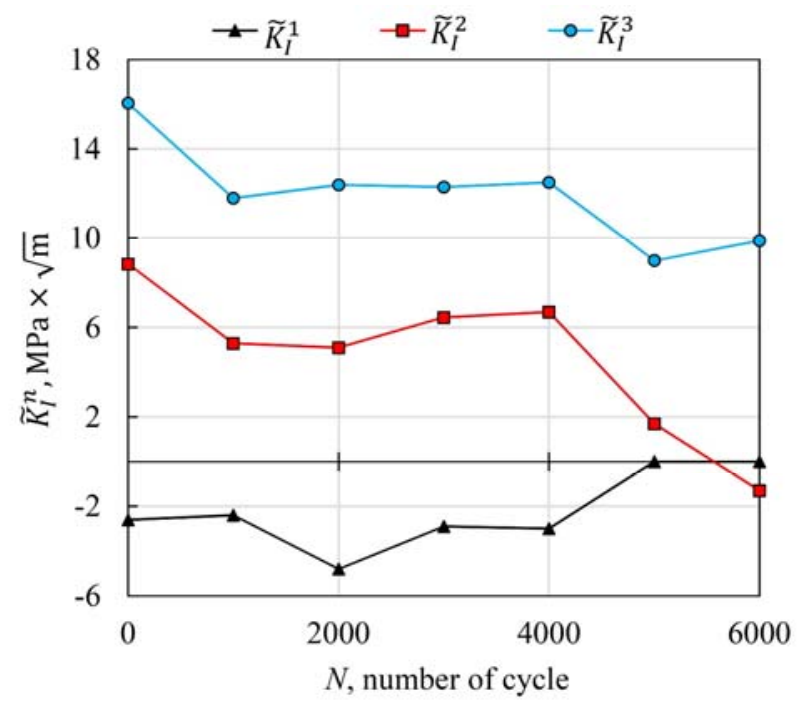

a

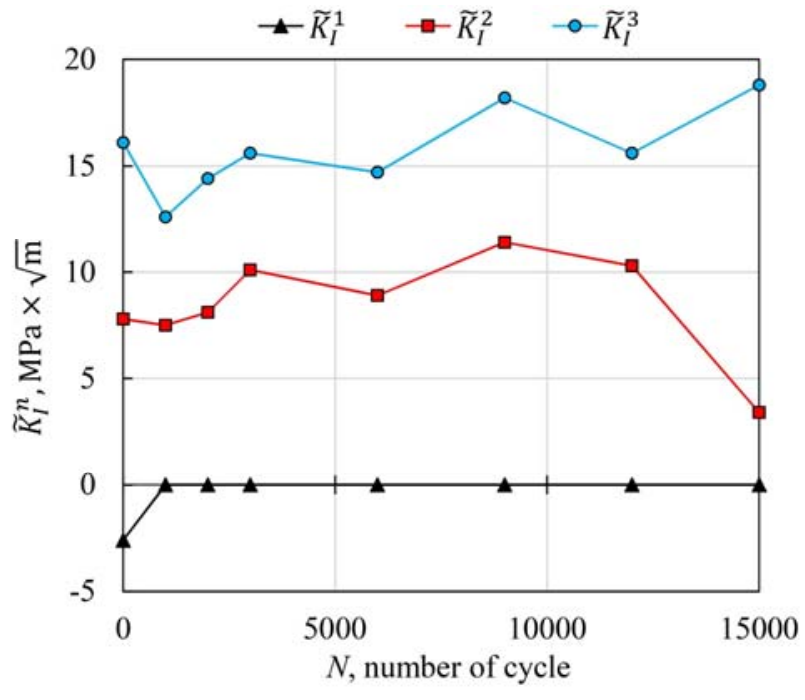

$\mathrm{b}$

Figure 7: Residual SIF $\tilde{K}_{I}^{n}$ values as a function of loading cycle number $N$ for T5-H1 (a) and T5-H2 (b) specimens for notches of length $\tilde{a}_{n}(\mathrm{n}=1,2,3)$.

Data, presented in Fig.6b, provide a way to derive SIF values, connected with residual stress only, by means of technique proposed in work [11]. The essence of this approach resides in implementing the linear superposition principal in order to evaluate SIF values $K_{I}^{n(R S)}$, which are related to pure residual stress field. In other words, $K_{I}^{n(R S)}$ can be presented as the difference in experimental SIF value $\tilde{K}_{I}^{n}$ and theoretical (numerical) SIF value $K_{I}^{n T}$, which are obtained for specimens of equal geometry with the same crack length under the same remote stress:

$$
\tilde{K}_{I}^{n(R S)}=\tilde{K}_{I}^{n}-K_{I}^{n T}
$$

where $\mathrm{n}=1,2$, 3. Theoretical SIF values $K_{I}^{1 T}$ are listed in Tab. 4. This table also includes $K_{I}^{1(R S)}$ values obtained by relationship (2) for notch of $\tilde{a}_{1}$ length proceeding from experimental data shown in Fig. $6 \mathrm{~b}$.

\begin{tabular}{ccccc}
\hline$\sigma, \mathrm{MPa}$ & $\tilde{a}_{1}, \mathrm{~mm}$ & $\tilde{K}_{I}^{n}, \mathrm{MPa} \times \sqrt{\mathrm{m}}$ & $K_{I}^{1 T}, \mathrm{MPa} \times \sqrt{\mathrm{m}}$ & $K_{I}^{1(R S)}, \mathrm{MPa} \times \sqrt{\mathrm{m}}$ \\
60 & 2.52 & -5.1 & 7.4 & -12.50 \\
80 & 2.30 & -2.6 & 9.66 & -12.26 \\
100 & 2.43 & 0 & 12.2 & -12.20 \\
\hline
\end{tabular}

Table 4: SIF values for different remote stress levels.

Data of Tab. 4 demonstrate that residual SIF values, calculated for different remote stress levels, coincide within 2.4 percent. This fact provides reason enough to implement linear fracture mechanics relations in the course of experimental SIF determination when a crack length met to the condition $\tilde{a}_{1} \geq 2 \mathrm{~mm}$. Thus, Formula (1) can be reliably used for residual SIF $K_{I}^{n(R S)}$ determination for all three notches of different length, emanating from cold-expanded holes at different stages of low-cycle fatigue. Dependencies of residual SIF values from number of loading cycle are shown in Fig. $8 \mathrm{a}$ and $8 \mathrm{~b}$ for specimens of T5-H1 and T5-H2 group, respectively. 


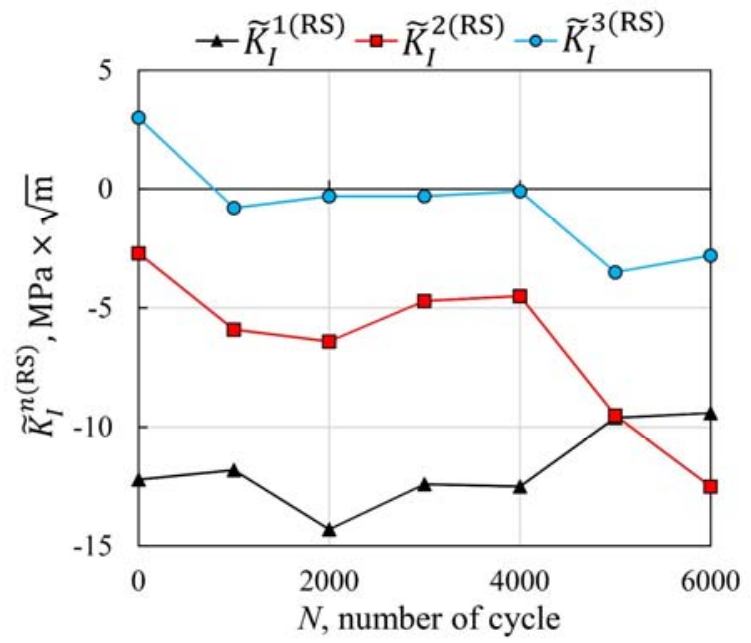

a

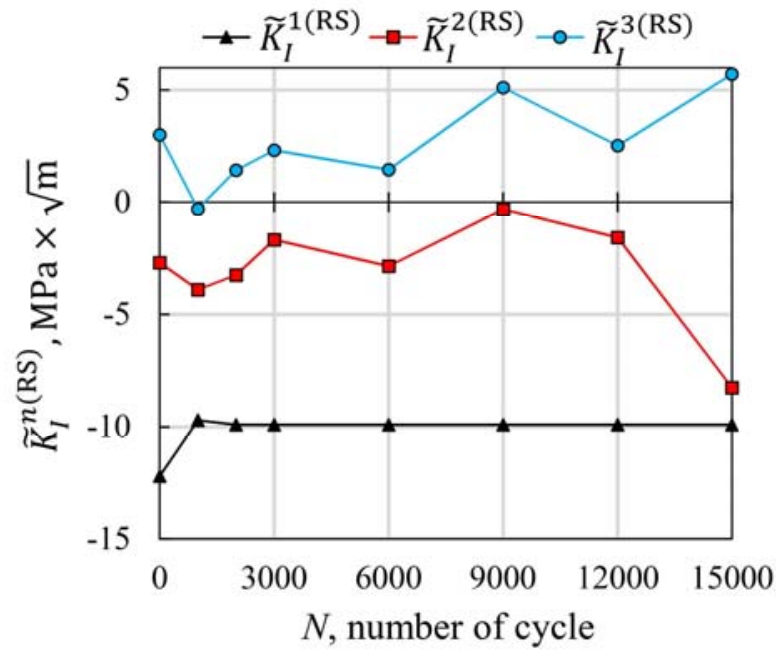

$\mathrm{b}$

Figure 8: Residual SIF $K_{I}^{1(R S)}$ values as a function of loading cycle number $N$ for T5-H1 (a) and T5-H2 (b) specimens for notches of length $\tilde{a}_{n}(\mathrm{n}=1,2,3)$.

Plots, presented in Fig. 8, indicate initial level of residual SIF $K_{I}^{n(R S)}$ values at different distances from cold-expanded hole edge and their evolution due to low-cycle fatigue. Note that this evolution for most of presented curves cannot be characterises as monotonic relaxation. Dependencies of residual stress SIF values $K_{I}^{n(R S)}$ from current crack length $\tilde{a}_{n}$ in specimens of both groups, constructed at different stages of low-cycle fatigue, are shown in Fig. 9. Curves in Fig. 8 and 9 evidence that an influence of negative residual stress takes place at distance $a_{2} \leq 4.10 \mathrm{~mm}$ from the hole edge for T5-H1 group and at distance $a_{2} \leq 4.50 \mathrm{~mm}$ for T5-H2 group. This influence is practically absence for $r_{0}+\tilde{a}_{3}$ radius for both cases.

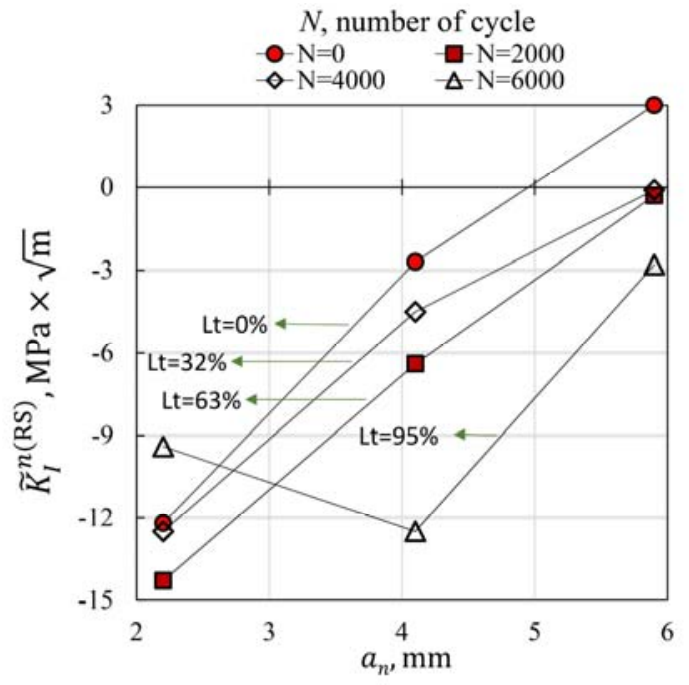

a

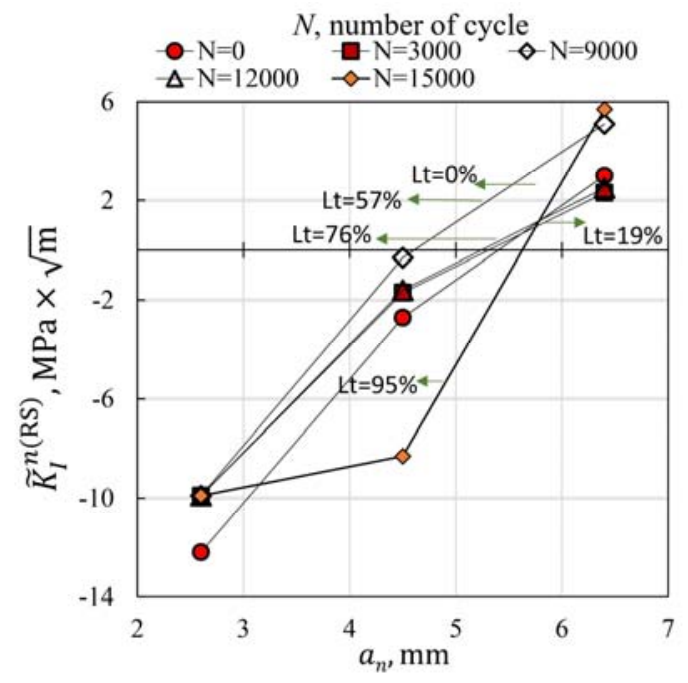

$\mathrm{b}$

Figure 9: Residual SIF $K_{I}^{n(R S)}$ values as a function of notches length $\tilde{a}_{n}(\mathrm{n}=1,2,3)$ for T5-H1 (a) and T5-H2 (b) specimens for different cycle number.

Averaged values of notch length, which are used for plots in Fig. 7 and Fig. 8, are listed in Tab. 5.

Normalizes dependencies of residual SIF values from loading cycle number, which follows from dependencies, shown in Fig. 8, could be used for quantitative estimation of degree of residual stress relaxation in the hole vicinity. Corresponding curves are presented in Fig. 10. Maximal relaxation reaches 23\% for specimens of T5-H1 group ( N = 6000 cycles) and 20\% for specimens of T5-H2 group ( $N=15000$ cycles). This fact means that for low-cycle fatigue with stress range 
$\Delta \sigma=350 \mathrm{MPa}$ the change of stress ratio from $R=-0.4$ to $R=-1.0$ does not influence on residual stress evolution. Both extreme values of relaxation parameter are reached for 95 per cent of lifetime.

\begin{tabular}{cccc}
\hline Specimen's group & $\tilde{a}_{1}, \mathrm{~mm}$ & $\tilde{a}_{2}, \mathrm{~mm}$ & $\tilde{a}_{3}, \mathrm{~mm}$ \\
T5-H1 & 2.20 & 4.10 & 5.90 \\
T5-H2 & 2.60 & 4.50 & 6.40 \\
\hline
\end{tabular}

Table 5: Averaged notch length.

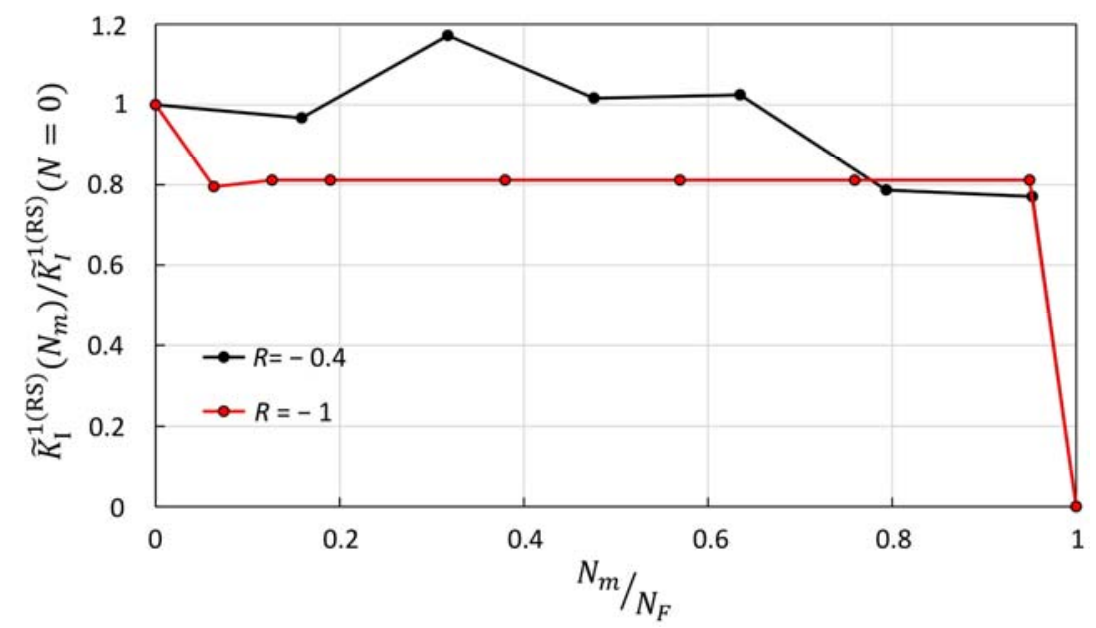

Figure 10: Normalized residual SIF values as a function of loading cycle number for notches of $\tilde{a}_{1}$ length.

It is of interest to obtain quantitative parameters of residual stress field under study. Rough but quite reliable estimation follows from the first term of Westergaard's decomposition [30]:

$$
\sigma_{2}^{R S}=\frac{K_{I}^{1(R S)}}{\sqrt{2 \pi r}}
$$

where $\sigma_{2}^{R S}$ denotes circumferential residual stress components, related to the first notch increment of $\tilde{a}_{1}$ length; $r$ is a distance from the notch tip along $x$-axis. Graphical representation of function (3) is shown in Fig. 11. Quantitative estimation that follows from formula (3) for $r=0.005 \mathrm{~mm}$ is $\sigma_{2}^{R S}=-220 \mathrm{MPa}$. This result is in a good agreement with numerical data presented in work [11].

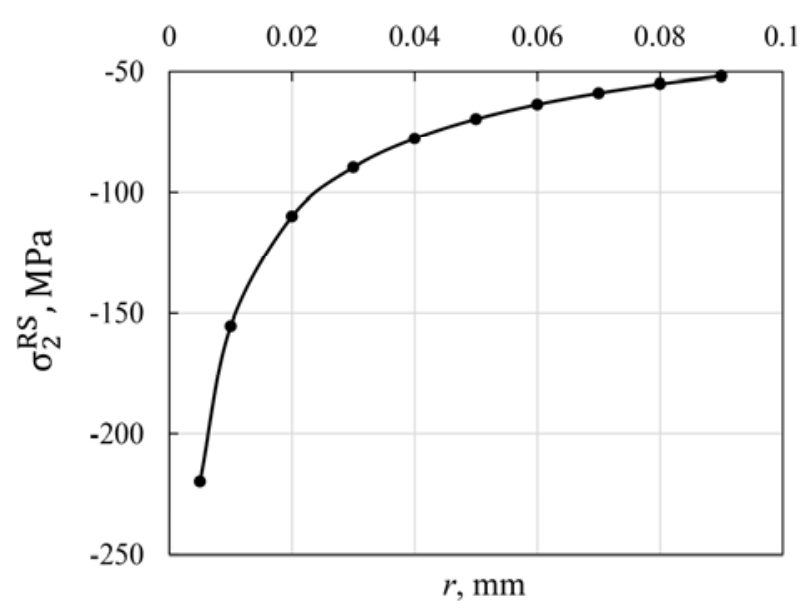

Figure 11: Values of circumferential residual stress component $\sigma_{2}^{R S}$ at different distances from the tip of notch of $\tilde{a}_{1}$ length. 


\section{CONCLUSION}

$\mathrm{U}$

nconventional method for a quantitative characterization of residual stress evolution near cold-expanded hole due to low-cycle fatigue is proposed and realized. The approach developed is based on modified version of the crack compliance method that is capable of SIF determination for narrow notches emanating from cold-expanded holes. These notches are inserted at different stages of low-cycle fatigue under constant external load. The first distinctive point of the technique involved consists of the fact that in-plane displacement components are measured by ESPI along narrow notch border immediately. Notch emanation from the hole edge is the second important trait, which considerably increases a sensitivity with respect to residual stress determination. The third feature resides in consideration of two low-cycle fatigue programs with negative stress ratio. Validity of implementation of linear fracture mechanics relationships for transition from experimentally determined displacement components to required SIF values in the cold-expanded hole vicinity is substantiated by comparing data, which are obtained for different external load values. Above assertion follows from linear character of dependencies of NMOD and SIF values, obtained in residual stress field, from remote stress level. This fact opens a way to implement the linear superposition principal for evaluation of residual SIF values. It is shown that residual SIF values, which correspond to different remote stress levels, lie within 2.4 per cent interval. Two loading programs are performed for stress range $\Delta \sigma=350 \mathrm{MPa}$. It is established that maximal residual stress relaxation is equal to $23 \%$ and $20 \%$ for stress ratio $R=-0.4$ to $R=-1.0$, respectively. The results obtained demonstrate that negative circumferential residual stress remains its positive influence on fatigue crack resistance during $95 \%$ of low-cycle lifetime of specimen with coldexpanded hole for both low-cycle fatigue programs.

\section{ACKNOWLEDGEMENTS}

he research was carried out within the frames of Subsidy Agreement 14.628.21.0009, Project identification number RFMEFI62818X0009 (Ministry of Science and High Education of the Russian Federation).

\section{REFERENCES}

[1] Matvienko, Y.G., Pisarev, V.S., Eleonsky, S.I. (2019). The effect of low-cycle fatigue on evolution of fracture mechanics parameters in residual stress field caused by cold hole expansion, Fratt. ed Int. Str., 13(47), pp. 303-320.

DOI: 10.3221/IGF-ESIS.47.23.

[2] Matvienko, Y.G., Pisarev, V.S., Eleonsky, S.I. (2019). The effect of low-cycle fatigue parameters on damage accumulation near a hole, Eng. Fail. An., 106, DOI: 10.1016/j.engfailanal.2019.104175.

[3] Wang, Z.-q., Huang, X.-g., Zhang, D.-h. (2020). Low cycle fatigue damage model and sensitivity analysis of fatigue crack initiation by finite element approach, Fratt. ed Int. Str., 14(53), pp. 81-91.

DOI: 10.3221/IGF-ESIS.53.07.

[4] Tumanov, A.V., Shlyannikov, V.N., Zakharov, A.P. (2020). Crack growth rate prediction based on damage accumulation functions for creep-fatigue interaction, Fratt. ed Int. Str., 14(52), pp. 299-309.

DOI: 10.3221/IGF-ESIS.52.23.

[5] Feistauer, E. E., dos Santos, J. F., Amancio-Filho, S. T. (2018). A Review on Direct Assembly of Through-the-Thickness Reinforced Metal-Polymer Composite Hybrid Structures, Polymer Engineering \& Science, 59(4), pp. 661-674. DOI: 10.1002/pen.25022.

[6] Reid, L. (2014). Hole Cold Expansion - The Fatigue Mitigation Game Changer of the Past 50 Years, Advanced Materials Research, 891-892, pp. 679-684. DOI: 10.4028/www.scientific.net/AMR.891-892.679.

[7] Stefanescu, D. (2004). Measurement and prediction of fatigue crack growth from cold expanded holes, part 1: the effect of fatigue crack growth on cold expansion residual stresses, J. of Str. Analysis, 39(1), pp. 25-39. DOI: $10.1177 / 030932470403900103$.

[8] Ball, D.L. (1995). Elastic-plastic stress analysis of cold expanded fastener holes, Fatigue and Fract.of Eng. Mat. and Struct., 18(1), pp. 47-63.

[9] Zhang, Y., Fitzpatrick, M.E., Edwards, L. (2005). Analysis of the residual stress around a cold-expanded fastener hole in a finite plate, Strain, 41(2), pp. 59-70. DOI:10.1111/j.1475-1305.2005.00181.x. 
[10] Pavier, M.J., Poussard, C.G.C., Smith D.J. (1999). Effect of residual stress around cold worked holes on fracture under superimposed mechanical load, Eng. Fract. Mechanics, 63(6), pp.751-773. DOI: 10.1016/s0013-7944(99)00050-8.

[11] Moreira, P.M.G.P., De Matos, P.F.P., Pinho, S.T., Pastrama, S.D., Camanho, P.P., De Castro, P.M.S.T. (2004). The Residual Stress Intensity Factors for Cold-Worked Cracked Holes: a Technical Note, Fatig. \& Fract. of Eng. Mat. \& Struct., (27), pp. 879-886. DOI:10.1111/j.1460-2695.2004.00768.x.

[12] Yongshou, L., Xiaojun, S., Jun, L., Yue Zhufeng. (2010). Finite element method and experimental investigation on the residual stress fields and fatigue performance of cold expansion hole, Materials and Design, 31(3), pp. 1208-1215. DOI: $10.1016 /$ j.matdes.2009.09.031.

[13] Mahendra Babu, N., Jagadish, T., Ramachandra, K., Sridhara, S. (2008). A simplified 3-D finite element simulation of cold expansion of a circular hole to capture through thickness variation of residual stresses. Eng. Fail. An., 15 (4), pp. 339-348. DOI: 10.1016/j.engfailanal.2007.02.003.

[14] Garcia-Granada, A.A., Pavier, M.J., Smith, D.J. (2001). A new procedure based on Sachs' boring for measuring nonaxisymmetric residual stresses, Int. J. of Mech. Sciences, 42(6), pp. 1027-1047. DOI: 10.1016/s0020-7403(99)00039-9.

[15] Garcia-Granada, A.A., Pavier, M.J., Smith, D.J. (2001). A new procedure based on Sachs' boring for measuring nonaxisymmetric residual stresses: experimental application, Int. J. of Mech. Sciences, 43(12), pp. 2753-2768. DOI: $10.1016 /$ s0020-7403(01)00071-6.

[16] Özdemir, A.T., Edwards, L. (2004). Through-thickness residual stress distribution after the cold expansion of fastener holes and its effects on fracturing, J. Eng. Mater. Technol., 126, pp. 129-135. DOI: 10.1115/1.1634278.

[17] Zuccarello, B., Di Franco, G. (2013). Numerical-experimental Method for the Analysis of Residual Stresses in Coldexpanded Holes, Exp. Mechanics; 53(4), pp. 673-686. DOI:10.1007/s11340-012-9669-2

[18] Backman, D., Cowal, C., Patterson, E.A. (2010). Analysis of the effects of cold expansion of holes using thermoelasticity and image correlation, Fat. \& Fract. of Eng. Mat. \& Struct., 33(12), pp. 859-870. DOI: $10.1111 /$ j.1460-2695.2010.01472.x

[19] Keith, W.J., Ralph, W.B. (2017). Investigation of residual stress relaxation in cold expanded holes by the slitting method, Eng. Fract. Mech., 179, pp. 213-224. DOI: 10.1016/j.engfracmech.2017.05.004

[20] Matvienko, Y.G., Pisarev, V.S., Eleonsky, S.I. (2019). Residual stress/strain evolution due to low-cycle fatigue by removing local material volume and optical interferometric data, Fat. \& Fract. of Eng. Mat. \& Struct., 42, pp. 20612078. DOI:10.1111/ffe.13083

[21] Pisarev, V.S., Odintsev, I.N., Eleonsky, S.I., Apalkov, A.A. (2018). Residual stress determination by optical interferometric measurements of hole diameter increments, Optics and Lasers in Engineering, 110, pp. 437-456, DOI: $10.1016 /$ j.optlaseng.2018.06.022

[22] Pisarev, V.S., Matvienko, Y.G., Eleonsky, S.I., Odintsev, I.N. (2017). Combining the crack compliance method and speckle interferometry data for determination of stress intensity factors and T-stresses, Eng. Fract. Mech., 179, pp. 348374. DOI: $10.1016 /$ j.engfracmech.2017.04.029

[23] Pisarev, V.S., Dzuba, A.S., Grigoriev, V.D., Chumak, S.V. (2001). Reference fringe patterns as effective tool for local strain analysis based on holographic interferometry data. 4th international workshop on automatic processing of fringe patterns, Bremen, September 17-19.

[24] Pisarev, V.S., Balalov, V.V. (2004). A role of fringe pattern catalogue in the course of interferometrically based determination of residual stresses by the hole-drilling method, Opt. \& L. in Eng., 41(2), pp. 411-462. DOI: $10.1016 /$ S0143-8166(02)00203-8

[25] Rastogi, P. (2001). Digital speckle pattern interferometry and related techniques, Wiley, West Sussex.

[26] Jogdand, P.V., Murthy, K.S.R.K. (2010). A finite element based interior collocation method for the computation of stress intensity factors and T-stresses, Eng. Fr. Mech., 77(7), pp. 1116-1127. DOI: 10.1016/j.engfracmech.2010.03.002.

[27] Pook, L. P., Campagnolo, A., Berto, F. (2016). Coupled fracture modes of discs and plates under anti-plane loading and a disc under in-plane shear loading, Fat. \& Fract. of Eng. Mat. \& Struct., 39(8), pp. 924-938. DOI: 10.1111/ffe.12389.

[28] Pook, L. P., Berto, F., Campagnolo, A.(2016). Coupled fracture modes under anti-plane loading, Fratt. ed Int. Str., 10(37), pp. 108-113. DOI: 10.3221/IGF-ESIS.37.15.

[29] Murakami, Y. (1987). Stress intensity factors handbook, Oxford: Pergamon.

[30] Westergaard, H.M. (1939). Bearing pressures and cracks, J. of App. Mech., 61, pp. A49-A59. 